\title{
Depth Prediction of Karstic-Fault Reservoirs Based on Wellbore Temperature Measurements and Numerical Simulations
}

\author{
Jian Lei, Baozhi Pan, Yuhang Guo $\mathbb{D}$, YuFei Fan, and Lihua Zhang \\ College of GeoExploration Science and Technology, Jilin University, Changchun 130026, China \\ Correspondence should be addressed to Yuhang Guo; 124563749@qq.com
}

Received 6 January 2020; Revised 27 May 2020; Accepted 3 June 2020; Published 22 June 2020

Academic Editor: Isabelle Chambefort

Copyright ( 2020 Jian Lei et al. This is an open access article distributed under the Creative Commons Attribution License, which permits unrestricted use, distribution, and reproduction in any medium, provided the original work is properly cited.

\begin{abstract}
Karstic-fault oil pools are a new type of carbonate reservoirs which is consisted of groups of large caves with high oil storage potential. In this study's examinations of high-yielding wells, it was found that many valuable reservoirs relate to the drilling wells through fractures or karst caves, and it was not possible to determine the reservoir depths through the method of seismic prospecting precisely due to its poor vertical resolution. The conventional logs cannot be run in the case of no mud circulation due to leaking to the caves. If the depths of the reservoirs cannot be determined, then it becomes difficult to achieve long term and stable development of the oil resources in the reservoirs. The heat transfer between wellbore and formation during oil production processes was simulated by CFD. The Horner method was used for estimating the flow temperature during the stable production stage using the temperature curve measured after shut-in. This research presented a scheme which could be used to effectively determine the depths of karstic-fault reservoirs by static and flow temperature logs. The proposed method was applied to a well located in the Tahe Oilfield of the Tarim Basin. The application of the method will aid in deepening our understanding of the distribution of fault-karst reservoirs, as well as in supporting the future stable and sustainable highyielding oilfield production of similar reservoirs.
\end{abstract}

\section{Introduction}

A new type of carbonate reservoir, referred to as karstic-fault systems, has been discovered in the Tahe Oilfield, Tarim Basin, in northwestern, China. This type of reservoir consists of a group of large caves which are interconnected by high permeability fractures or large caves, characterized by poor matrix porosity and permeability $[1,2]$. The karst caves have been observed to be distributed randomly, discretely, and discontinuously along the deep faults [3]. However, there potential certainly exists for significant oil production once the karstic-fault systems have related to production wells $[4,5]$. The investigation conducted by Li Yang [6] found that the cave reservoirs contributed to more than $95 \%$ of the productivity in those blocks which had been put into development in the Tahe Oilfield.

However, it has been found that accurate depth predictions in karstic-fault carbonate reservoirs are challenging problems, since the reservoirs are highly heterogeneous and ultradeep, with known depth ranges of $5,000 \mathrm{~m}$ to $7,000 \mathrm{~m}$
[7]. It has been observed that particularly after a period of production, the caves which are connected to the production wells tend to be replenished with oil from deeper deposits. At such times, it is urgent to determine the reservoir depths in order to update the understanding of the reservoir situations, as well as the development plans.

It has been found that the caves in karstic-fault systems develop longitudinally [8]. In addition, when drilling activities move closer to the target horizon, there will be a great deal of mud leakage, which makes it impossible to continue the drilling processes. If mud leakage occurs after drilling to a certain depth, then the drilling can be smoothly resumed after effective plugging measures have been taken [9]. However, many lost points and significant leakages may occur within the karstic-fault systems, and sealing effects have been found to be frequently useless. In other words, the mud loss layers are not completely blocked, or repeated losses may result from the lifting and lowering of the drilling tools. Subsequently, the drilling operations will be impeded and the measurements will be affected, resulting in the loss of 


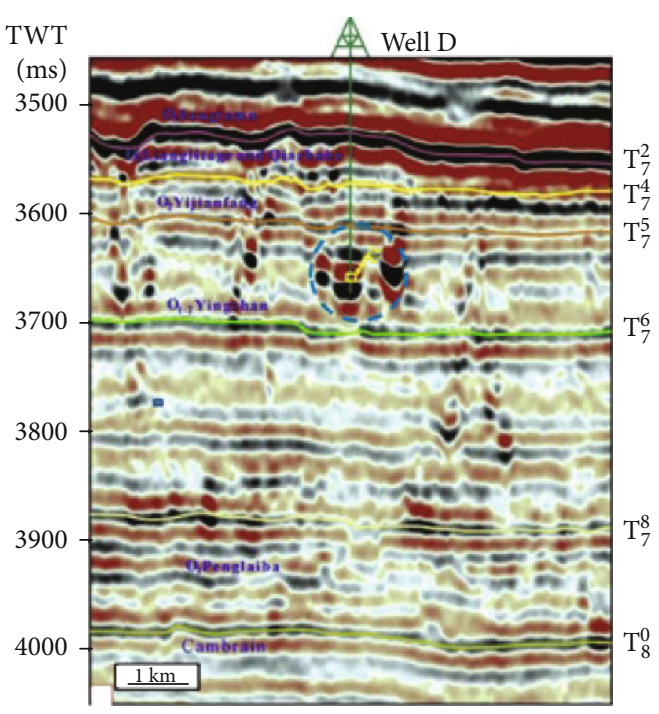

(a)

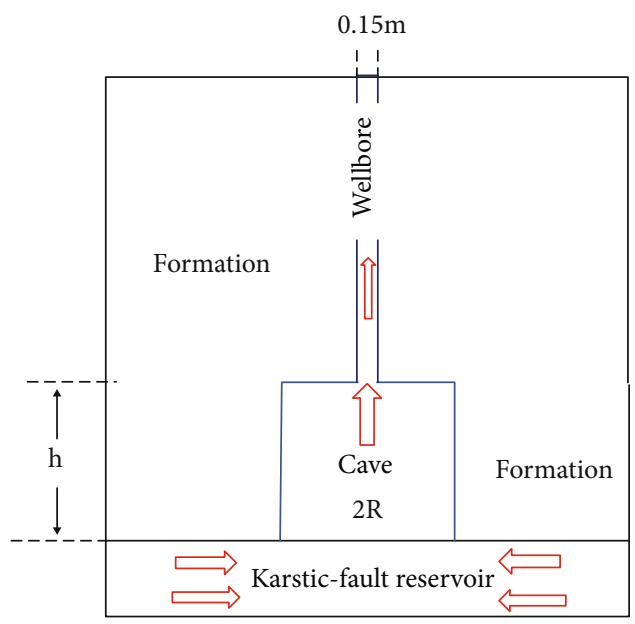

(b)

Figure 1: (a) Seismic image of karstic-fault reservoir [7]. (b) Schematic of production well, $h$ is the depth difference between the bottom-hole and the reservoir.

open-hole logging data and in the inability to accurately determine the reservoir depths [10].

As a type of geothermal heat indicator, the temperature data have been considered to be a natural tracer of groundwater or oil flow in such fields as geothermal energy, oil and gas, and groundwater research [11-13]. It appears to be a promising approach for characterizing the connectivity patterns of those types of main flow paths $[14,15]$.

Temperature profiles along wellbores can be easily and continuously obtained using temperature probes in observational wellbores [16]. Temperature logs are records of moments in transient processes caused by the shut-in (cooling) and production (heating) processes. During the production of karstic-fault reservoirs, both the temperatures of the wellbores and surrounding formations tend to increase. If production processes are continued over a long period of time, then the temperatures of the wellbores will become stable. This is referred to as the flow temperature. After shut-in, the formation and wellbore temperature return to the initial temperature. The temperature log data are normally measured during the shut-in state and are also related to the shut-in times [17].

In recent years, the development of numerical simulation processes has provided a convenient and effective means to study both temperature and flow fields [18]. The computational fluid dynamics (CFD) technique was implemented to analyze the flow behavior of oil in wells and caves, because CFD makes it possible to numerically solve flow, mass, and energy balances [19]. This study found that in the previous related research reports, the adopted transient wellbore simulations had mainly focused on the mud circulation during the drilling and subsequent shut-in stages. The purpose of this study was to estimate the initial formation temperatures in order to determine the composition of the drilling fluids and the thickening times of the cement slurry [20-22].
In this study, the variations in the wellbore and formation temperature fields under production and shut-in modes were simulated. The relationship between the temperature levels and time was summarized from the obtained results. Then, based on this study's findings, the Horner method was used to predict the flow temperatures at specific production times using the shut-in temperatures. At the same time, the influences of the karst cave parameters on the temperatures in the wells were discussed, and a method to predict the cave lengths was formulated. Finally, a multistage approach was proposed for the purpose of determining the depths of karstic-fault reservoirs using the well temperature logs. The method was then applied to a well in the Shunbei area of the Tahe Oilfield, and promising application results were obtained.

\section{Background and Methodology}

2.1. Geological Feature and Physical Model. It has been observed that large caves tend to generate "bright spots" in seismic images, which are produced by the high-reflection energy in a plane (Figure 1(a)). The positions of these "bright spot" seismic facies have been found to generally leak drilling mud, and the wells are characterized by high and stable oil production. In Figure 1(a), the area circled by a blue dotted line indicates a karst cave area. This area had been targeted by the drillers but could not be drilled through. In the study area, following the onset of production in well $\mathrm{D}$, a considerable flow of industrial oil was obtained. The researchers believed that the oil had originated from the bottom of the karst cave [7].

The schematic diagram in Figure 1(b) details this study's geometric model of the simulations and shows the oil production process. As indicated in Figure 1(b), this study's physical model was divided into the three following sections: 
(a) wellbore, (b) surrounding formation, and (c) cave (as the flow channel). The karstic cave was located at the bottomhole area, which could not be accurately measured by the logging data. The oil had entered the well through that flow channel. The symbol $h$ in Figure 1(b) indicates the depth differences between the bottom-hole and the reservoir; in Figure $1(\mathrm{~b}), 0.15 \mathrm{~m}$ is the wellbore diameter; $R$ is the radius of a cavern as a flow channel; and $50 \mathrm{~m}$ was selected as the research object in this study, in accordance with the proportions described in Figure 1(a).

2.2. Methodology. It has been found that in deep underground drillings, the temperature-depth profiles are approximately straight lines, and the slope of the line represents the geothermal gradients. In addition, when there are no external interference effects, the temperature balance will be maintained. However, once the formation fluid begins to flow, the thermal balance will be destroyed. In this study, the focus was on the examination of karstic-fault reservoirs (typically below $6,000 \mathrm{~m}$ in depth). It is generally considered that the vertical flow of thermal fluid from karstic-fault reservoirs are the main causes of geothermal anomalies.

The three types of temperature and flow patterns for the observed well and reservoir are shown in Figure 2. This study focused on distinguishing whether the well and reservoir were directly connected or connected through the cave system. In such a system, the heat tends to be carried via vertical wellbore flow and then dissipates to the surrounding rock. However, it has been observed that when the relative positions of the reservoirs and wells are different, then the flow and static temperature curves measured in the wells will also significantly differ. In the cases where the wells are directly connected to the reservoir, the intersection of the static and flow temperature curves will be located in the reservoir area, as detailed in Figures 2(a) and 2(b). However, when they are connected by caves, there will be no intersection in the well area, as illustrated in Figure 2(c).

The third case detailed in Figure 2 was that which was mainly discussed in this study. It was expected that the temperature extension line would intersect below the curve. However, it was unclear how the intersection should be determined. The inversion framework proposed in this study had the following three main steps:

(1) Gathering of the well parameters: the well parameters included the radius and depth, oil and formation properties, and well temperature

(2) Determination of the flow temperature curve during the production period: the numerical simulation results indicated that the well temperature would change greatly in a very short period after the shutin. Due to the different radii, the heat transfer efficiency between the fluids in the well and the surrounding formations was different from that between the fluids in the karst cave and the surrounding formations. It was found that during the production period, the fluid temperature is continuous at the connection between the well and the cave. However, the tempera- ture recovery rates would be different after the shut-in. It was impossible to directly predict the temperature changes in the cave from the well temperature curve during the shut-in state, and the reservoir depth could not be inferred. Therefore, it was necessary to determine the well flow temperature during the production period

(3) Calculation of the reservoir depth: when oil flows into a wellbore from a reservoir through a karst cave, the bottom-hole flow temperature is related to the reservoir depth, cave radius, and flow velocity. Therefore, the reservoir depth could be inferred using the properties of the oil, well production data, and temperature values

2.3. Numerical Simulation. The numerical simulations in this research study were divided into two independent sections, which utilized the same software and calculation parameters. The first section was the simulation of well and surrounding formation temperature field during the production and shutin periods. The simulation results were used to summarize the methods for determining the flow temperature. The second section consisted of the simulation of the temperature values with the changes in the cave parameters. A method by which to determine the longitudinal length of the karst cave was proposed based on the simulation results.

2.3.1. Governing Equations. In the numerical simulations, the mass conservation, momentum conservation, and energy conservation controlled the flow and heat transfer rates $[23,24]$. The control equations are as follows:

momentum conservation

$$
\frac{\partial(\rho u)}{\partial t}+\rho(u \cdot \nabla) u=\nabla \cdot\left[-p+\mu\left(\nabla u+(\nabla u)^{\tau}\right)\right]+F
$$

mass conservation

$$
\frac{\partial \rho}{\partial t}+\rho \nabla \cdot(u)=0
$$

energy conservation

$$
\begin{gathered}
\frac{\partial\left(\rho C_{\rho} T\right)}{\partial t}+\rho C_{\rho} u . \nabla T+\nabla q=Q \\
q=-\lambda \nabla T
\end{gathered}
$$

where $\rho$ is the fluid density, $\mathrm{kg} / \mathrm{cm}^{3} ; u$ is the flow velocity, $\mathrm{m} / \mathrm{s} ; \mu$ is the fluid viscosity, $\mathrm{Pa} \cdot \mathrm{s} ; p$ is the pressure, $\mathrm{pa} ; C_{p}$ is the constant pressure heat capacity, $\mathrm{J} /(\mathrm{kg} \cdot) ; q$ is the heat flux, $\mathrm{W} / \mathrm{m}^{2} ; \lambda$ is the thermal conductivity, $\mathrm{W} /(\mathrm{m} \cdot \mathrm{k}) ; \mathrm{T}$ is the temperature, $\mathrm{k} ; \mathrm{F}$ represents the influence of volume force, and the gravity is not considered in this paper, $F=0$. Q represents the influence of the heat source that has been ignored in this paper, so $Q$ is equal to 0 . 

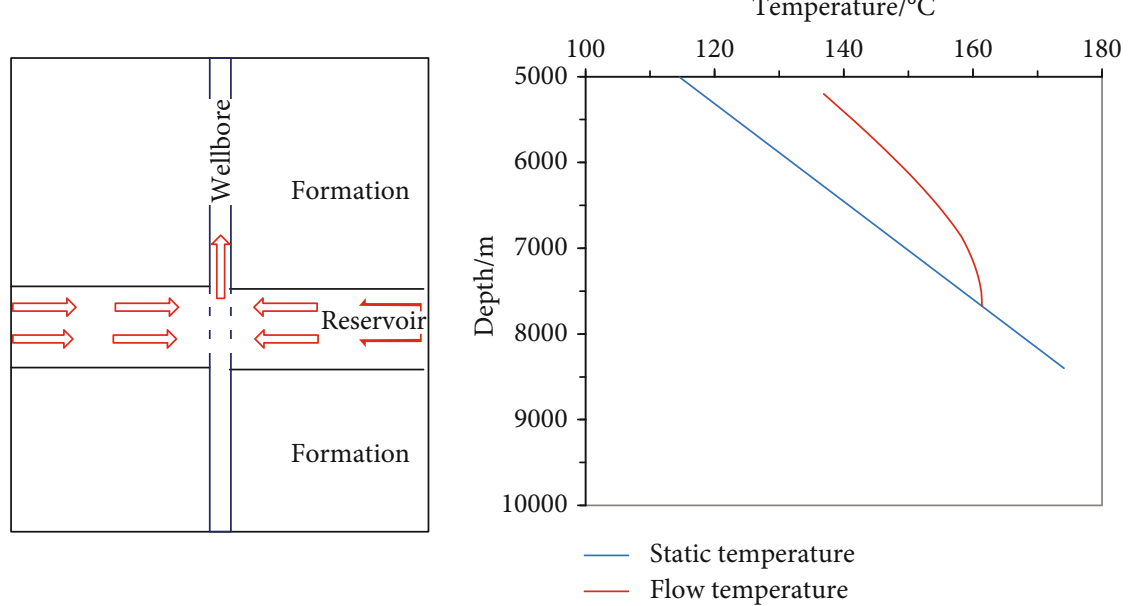

(a)
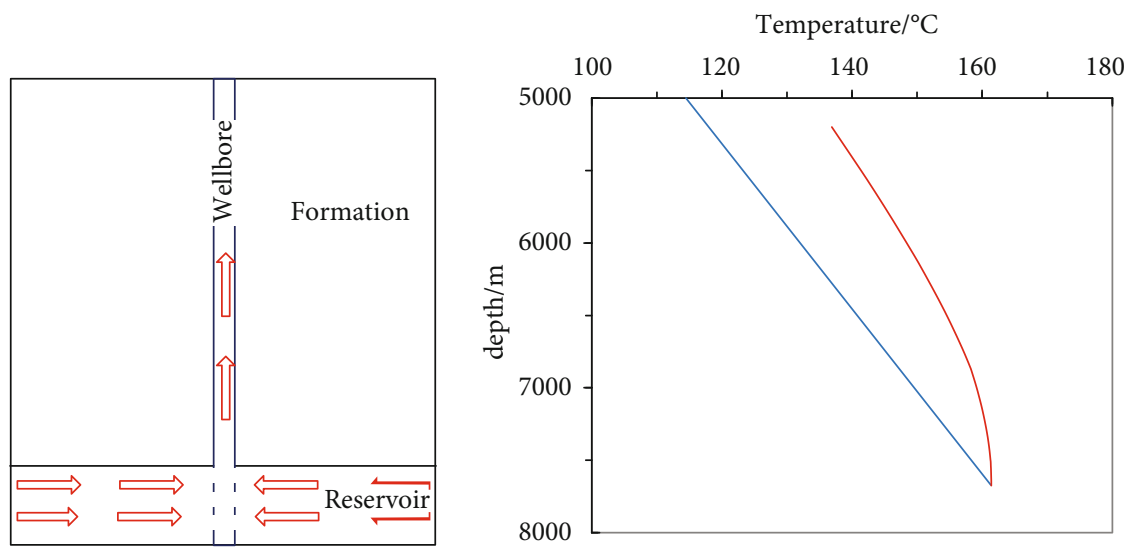

8000

- Static temperature

- Flow temperature

(b)
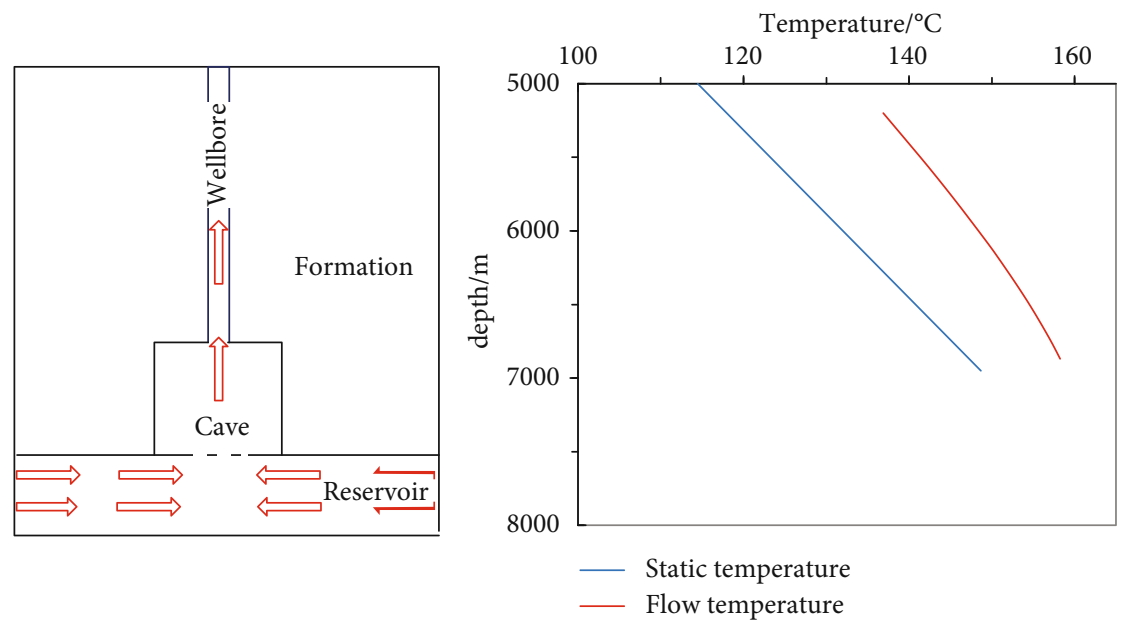

(c)

FIgURE 2: Illustration of temperature fields for production wells at different reservoir locations: (a) middle; (b) bottom; (c) below.

2.3.2. Thermal Boundary Conditions. The radial infinite and the bottom of formation maintain the initial temperature

$$
T_{\Omega}=T_{0}+g_{T} \cdot z
$$

The flow inlet was located at the bottom of the model, and the equations were as follows: 


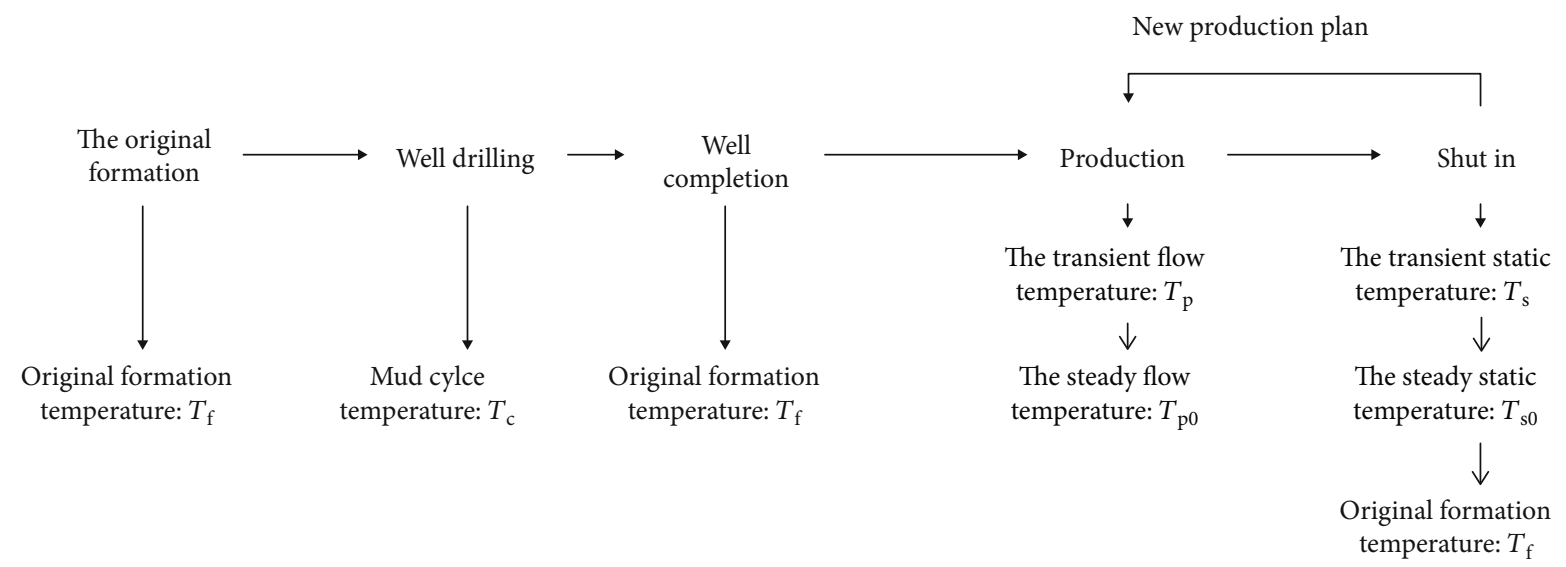

FIGURE 3: Well development stages and corresponding temperatures.

$$
u_{\text {in }}= \begin{cases}v & \text { production status } \\ 0 & \text { shut }- \text { in status }\end{cases}
$$

The flow outlet is at the top of the model

$$
p_{\text {out }}=0
$$

Where $T_{\Omega}$ is the temperature of formation boundary, k; $T_{0}$ is the surface temperature, $\mathrm{k} ; g_{T}$ is the geothermal gradient, $\mathrm{k} / \mathrm{m} ; z$ is the formation depth, $\mathrm{m} ; T_{\text {in }}$ is the inlet fluid temperature, $\mathrm{k} ; u_{\text {in }}$ is the fluid velocity at the inlet, $\mathrm{m} / \mathrm{s} ; v$ is the fluid inflow velocity, $\mathrm{m} / \mathrm{s} ; p_{\text {out }}$ is the outlet pressure, pa.

2.4. Parameters. The following stages were required to be completed, in order, from a development plan to stable oil production: drilling, completion, and production. Then, following the completion and production stages, the shut-in stage would be conducted from time to time. The well temperature measurements were made during the shut-in periods, and the logs were used to monitor the production conditions in order to develop new development plans. The well temperatures measured during the different development stages held different meanings. In this study, for the convenience of understanding, the symbols shown in Figure 3 were used to distinguish the different well temperature meanings.

The simulation parameters used in this study are shown in Table 1, in which the changes in density and viscosity with temperature and pressure were not considered.

2.5. Mesh Generation. Since the wellbore radius was $0.075 \mathrm{~m}$ and the karst cave radius was $50 \mathrm{~m}$, the size difference was extremely large. Therefore, when the two parts were modeled, the quality of the grid was very poor. In order to address this issue, the two parts were separately simulated. The results of cave simulations could then be used as the input of the wellbore simulations. An unstructured grid was used in the simulation. Figure 4 is the schematic diagram of mesh. The number of nodes in the radial boundary of the formation is set to 50 . The grids are radially distributed from the interface to the formation boundary [25]. The grids of wellbore center are refinement. The further the mesh is from the inter-
TABLE 1: Simulation parameters.

\begin{tabular}{lccc}
\hline Name & Symbol & Unit & Value \\
\hline Oil density & $\rho$ & $\mathrm{kg} / \mathrm{m}^{3}$ & 796 \\
Oil constant pressure heat capacity & $C_{p}$ & $\mathrm{~J} /(\mathrm{kg} \cdot \mathrm{k})$ & 2200 \\
Oil viscosity & $\mu$ & $\mathrm{Pa} \cdot \mathrm{s}$ & 0.002 \\
Oil thermal conductivity & $\lambda$ & $\mathrm{W} /(\mathrm{m} \cdot \mathrm{k})$ & 1 \\
Formation density & $\rho_{f}$ & $\mathrm{~kg} / \mathrm{m}^{3}$ & 2715 \\
Formation constant pressure heat & $C_{f}$ & $\mathrm{~J} /(\mathrm{kg} \cdot \mathrm{k})$ & 700 \\
capacity & $\lambda_{f}$ & $\mathrm{~W} /(\mathrm{m} \cdot \mathrm{k})$ & 3.1 \\
Formation thermal conductivity & $g_{T}$ & $\mathrm{k} / \mathrm{m}$ & 0.0178 \\
Geothermal gradient & $T_{0}$ & $\mathrm{k}$ & 20 \\
Surface temperature & $v$ & $\mathrm{~kg} / \mathrm{s}$ & 1.39 \\
Oil inflow velocity & \multicolumn{3}{c}{} \\
\hline
\end{tabular}

face, the larger the size will be. The boundary layer of interface is refined with the inflation method. Five layers of inflation were set at the wellbore side of the interface, and 10 layers of inflation were set at the formation side. The inflation thickness closest to the interface was $0.002 \mathrm{~m}$ and then increased successively. The maximum length of the grids set vertically is $0.5 \mathrm{~m}$, so the number of grids in the whole model exceeds $1,000,000$.

\section{Results}

3.1. Well Temperature during Production Period. During the simulation process, the longitudinal lengths of the wellbore and surrounding formations were $500 \mathrm{~m}$, and the formations were homogeneous and isotropic. The wellbore radius was set as $0.075 \mathrm{~m}$, and the formation radius was $30 \mathrm{~m}$. The bottom-hole depth was $7,250 \mathrm{~m}$, and the $h$ was $0 \mathrm{~m}$. Figure 5 illustrates a cross-sectional view of the wellbore and the formation temperature after production began in the well. During the production process, high-temperature fluid flowed through the wellbore. The fluid was then cooled, and the formation temperature had risen. Figure 6 shows the changes in the formation radial temperature distribution over time around the well at a depth of $7,000 \mathrm{~m}$. The 


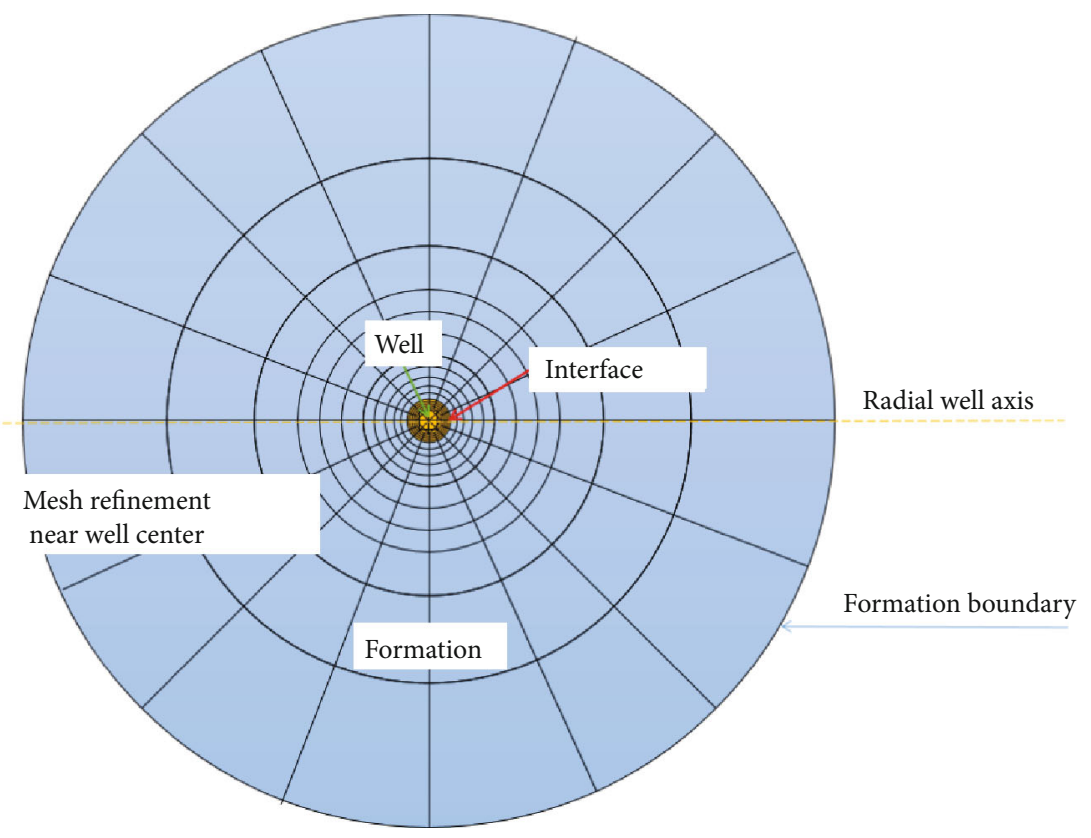

Figure 4: Schematic diagram of mesh.

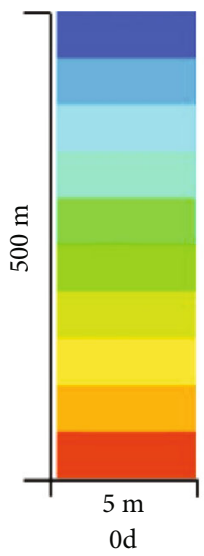

(a)

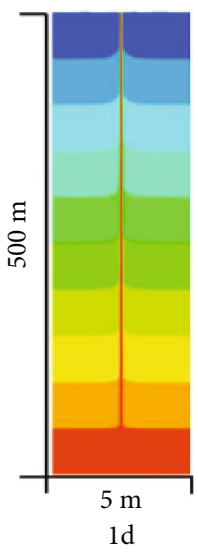

(b)

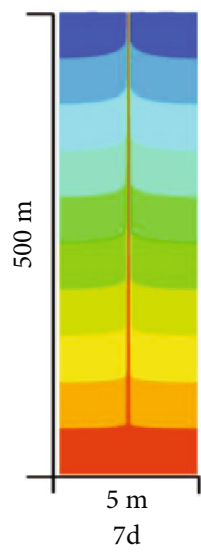

(c)

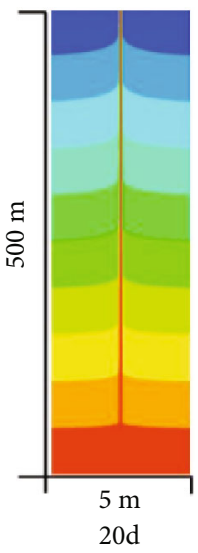

(d)

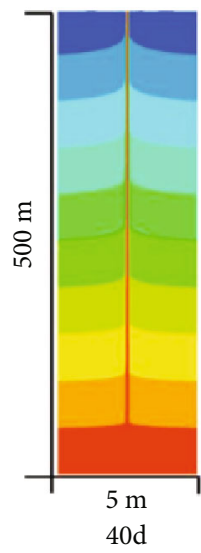

(e)

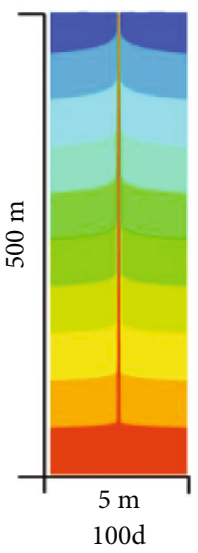

(f)

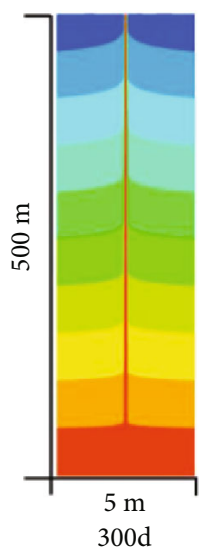

(g)

Figure 5: Temperature distribution at different times during production.

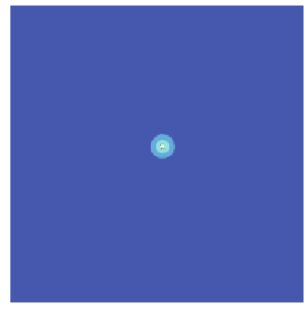

(a) $0 \mathrm{~d}$

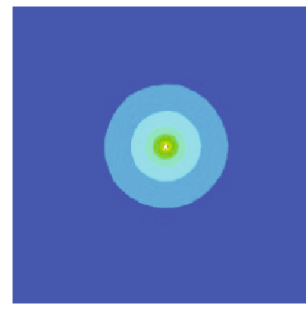

(b) $20 \mathrm{~d}$

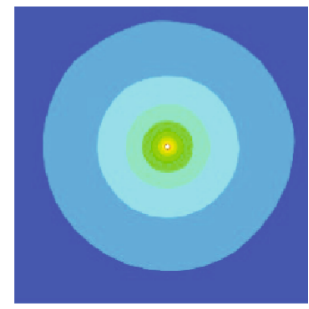

(c) $100 \mathrm{~d}$

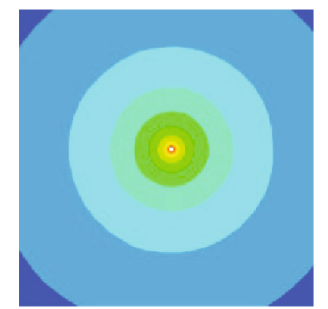

(d) $200 \mathrm{~d}$

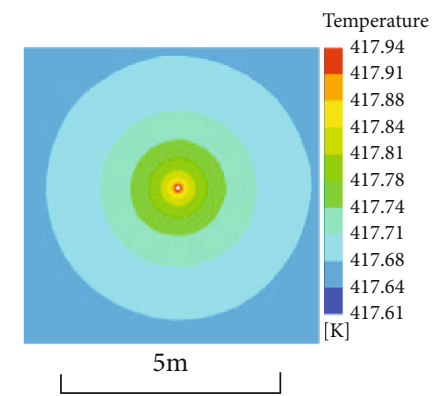

(e) $300 \mathrm{~d}$

FIGURE 6: Temperature distribution of the formation around the well during production at $7000 \mathrm{~m}$.

temperature changes in the formations were relatively gentle when compared to the sharp changes observed in the fluid temperature in the well. The reasons for this were that the formations had contained no fluid, and that the scale was significantly larger. As the production time continued, the heat continued to spread into the surrounding formations, and 


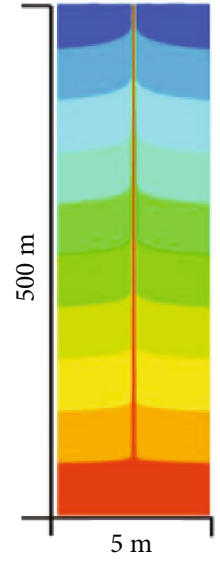

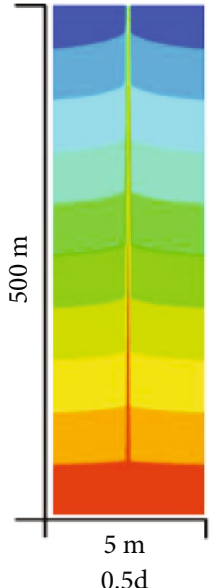

(b)

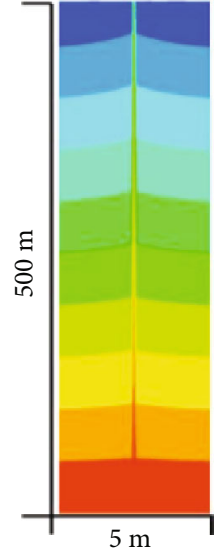

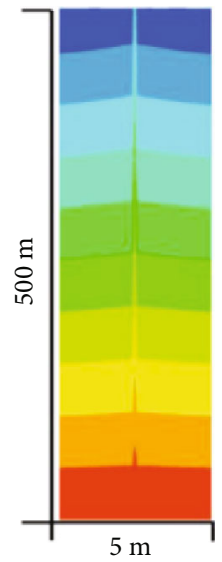

(d)

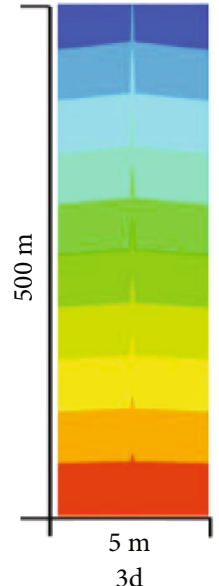

(e)

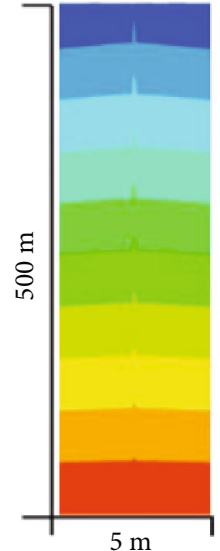

$4 \mathrm{~d}$

(f)

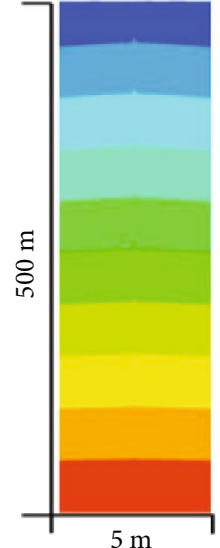

$6 \mathrm{~d}$

(g)

Figure 7: Temperature distribution at different times after shut-in.

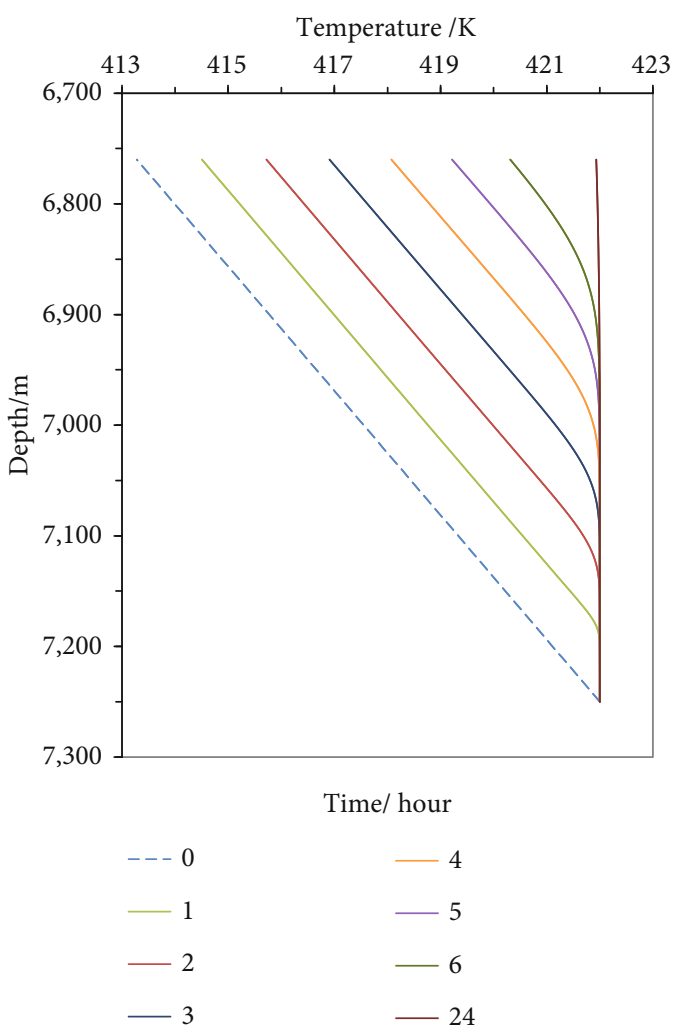

(a)

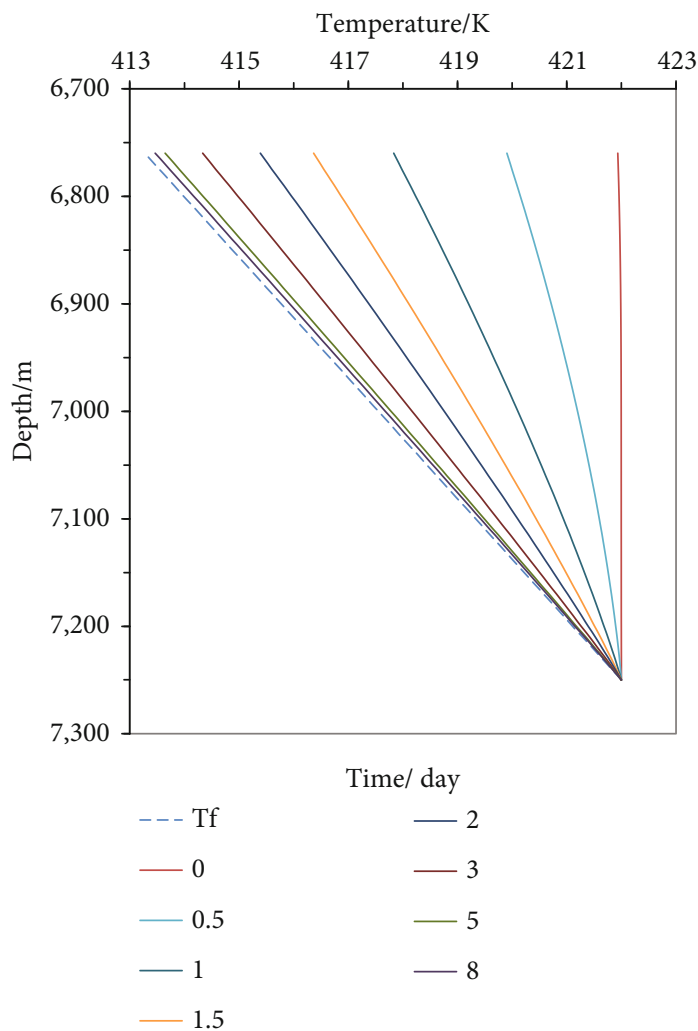

(b)

FIgURE 8: Wellbore temperature distribution at different times. (a) During production. (b) After shut-in.

the temperature levels in the formations located around the well continued to rise. At the same time, the temperature levels in the well had tended to stabilize after one day.

\subsection{Well Temperature during Shut-in Period. Figure 7 shows} a cross-section of the temperature recovery process during a shut-in period which occurred after 100 days of stable production. Following the shut-in, the wellbore and formation temperature levels gradually returned to the initial formation temperature. Therefore, it was determined that the length of production time exerted an effect on the temperature recovery following the shut-in period.

3.3. Horner Method (HM). Figure 8(a) details the wellbore temperatures at different times during the production process. The dotted line in the figure indicates the initial formation temperature, and the solid lines represent the transient flow temperatures during the different times (counted in days). It was observed that after production had begun, the wellbore temperature began to rise and then quickly reached 
a plateau level. Then, after the shut-in, the temperature level in the wellbore began to drop. The temperature levels were observed to drop the fastest in the first three days, and then had clearly decelerated (Figure $7(\mathrm{~b})$ ). In addition, during the early stages of the shut-in period, the temperature levels of the wellbore fluid rapidly decreased due to the fluid no longer flowing, and the heat not being vertically transferred through the wellbore. The efficiency of vertical convection by the oil was determined to be higher than the radial heat conduction during well heat transfer. Therefore, the formation temperature levels slowly changed, while the wellbore temperature levels were observed to change quickly.

The Horner method (HM) is widely used in the field of petroleum reservoir engineering to process the temperature and pressure recovery data for wells which are producing at constant flow rates. The initial formation temperatures can be estimated by examining the temperature values at different times following the shut-in period on semilogarithmic plots [26].

$$
T_{S}=T_{f}+M \ln \left(\frac{t_{c}+t_{s}}{t_{s}}\right) M=\frac{q}{4 \pi \lambda_{f}}
$$

Where $t_{s}$ denotes the production time, $\mathrm{d} ; t_{c}$ is the shut-in time, $\mathrm{d}$; and $q$ indicates the heat flow rate per unit of length. Therefore, from the formulated semilog plots, the undisturbed formation temperatures and parameter $M$ can be obtained.

As shown in Figure 8, this study's selected depths were $6,750 \mathrm{~m}, 7,000 \mathrm{~m}$, and $7,125 \mathrm{~m}$, and the temperatures at the different shut-in times were draw on a semilogarithmic plot. It can be seen in the figure that the temperature recovery curve could be divided into three regions, and the curve shape of Region II was consistent with Eq. 9. In addition when the curve was in Region I, then the shut-in time was very short and the temperature level in the well had changed only slightly. When the curve was in Region III, the shut-in duration was long enough that the temperature in the well had almost returned to the initial formation temperature. It was observed that when the production times were short, Region III may not have been as obvious, and the steady flow temperature during production would need to be determined using the temperature data in Region II. If the production time was short, then the time gap between temperature measurements after shut-in should be reduced appropriately. When the production time was relatively short, then $\left(t_{c}+t_{s}\right) / t_{s}$ in Eq. 9 changes. The segmentation values of different regions in Figure 9 also need to be reconsidered. Specific parameters should be selected according to the production data and temperature data of a specific production well.

3.4. Well Temperature and $h$. In the present study, in order to determine the longitudinal length of the karst cave, the relationship between the length of the karst cave and the temperature of the bottom hole was determined using numerical simulations. In the simulations, the radius of the karst cave as the flow channel was $50 \mathrm{~m}$, and the formation radius was $500 \mathrm{~m}$. The depth of bottom-hole was set as 7,400 m. The

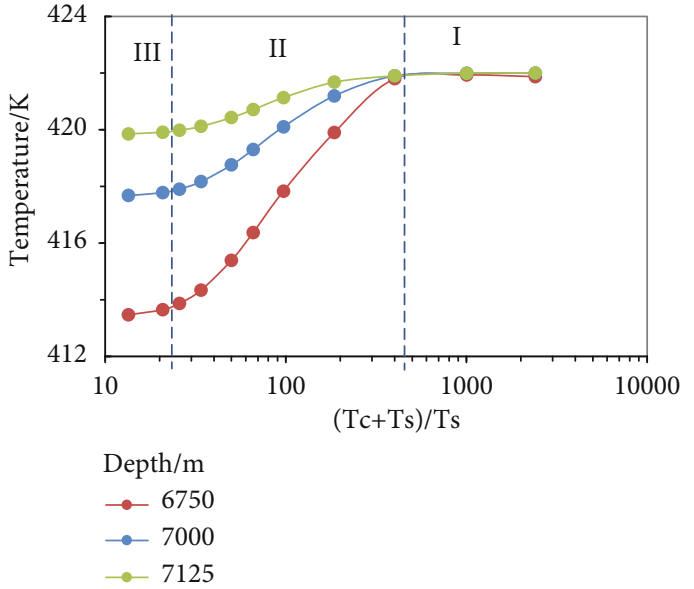

Figure 9: Temperature recovery curve after shut-in.

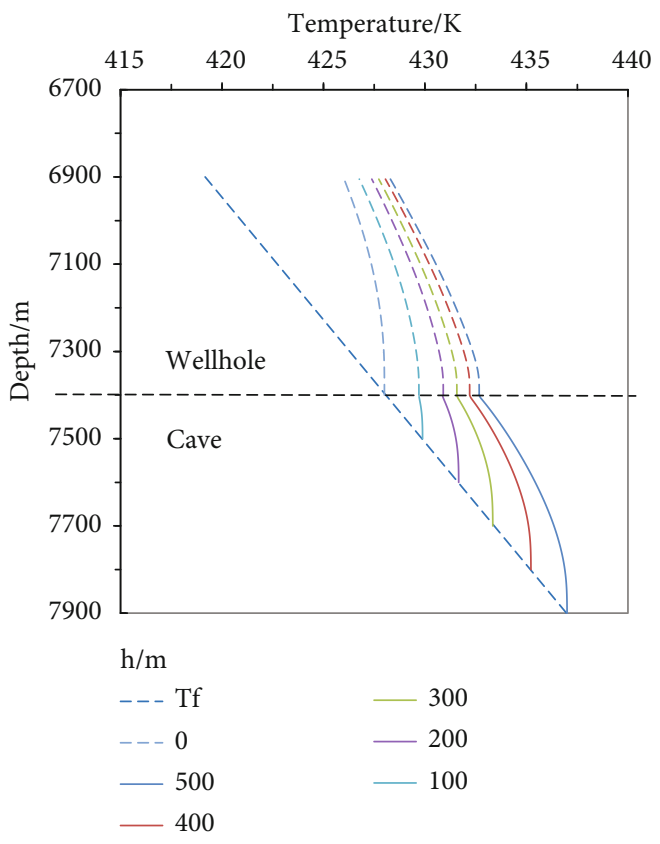

Figure 10: The temperature in the cave and wellbore.

temperature changes of the oil production processes in the karst cave and wellbore were simulated with $h$ changing. The results are shown in Figure 10.

The temperature differences of bottom-hole were used to determine $h$, and then the depth of the reservoir was determined. Figure 11 shows the temperature distribution in the karst cave and the relationship between $h$ and $\nabla \mathrm{Tb}$, where $\nabla \mathrm{Tb}$ represents the temperature differences in the steady flow temperature and static temperature at the bottom-hole.

In this present study, when the bottom-hole flow temperature was known, then the reservoir temperature could be obtained using Eq. (9). Subsequently, the $h$ and reservoir depth could be accurately determined.

$$
h=18.313 \nabla T b^{2}+19.545 \nabla T b
$$




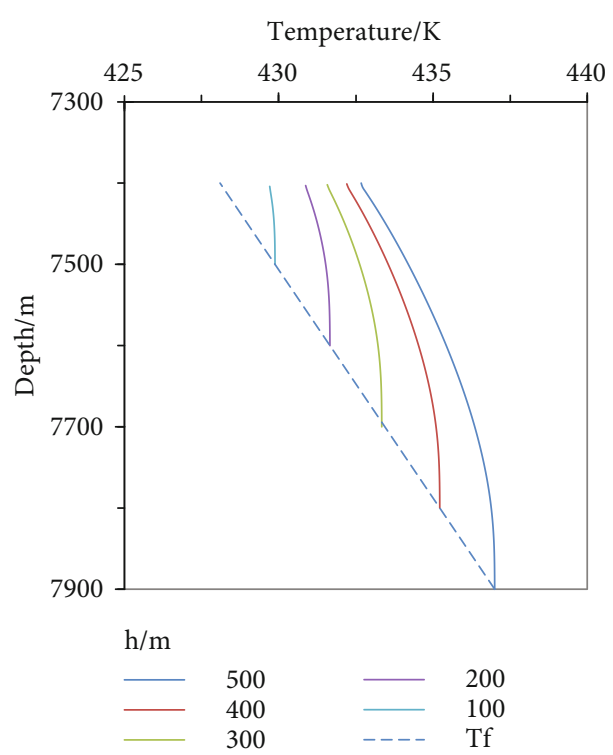

(a)

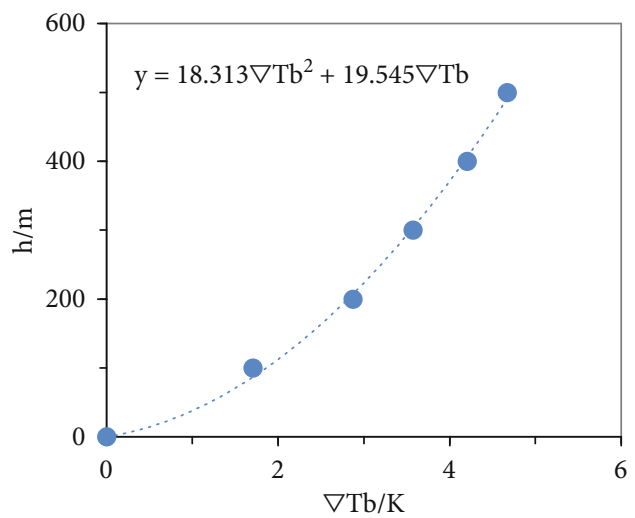

(b)

Figure 11: (a) Temperature distribution in karst cave. (b) Relationship between $h$ and $\nabla \mathrm{Tb}$.

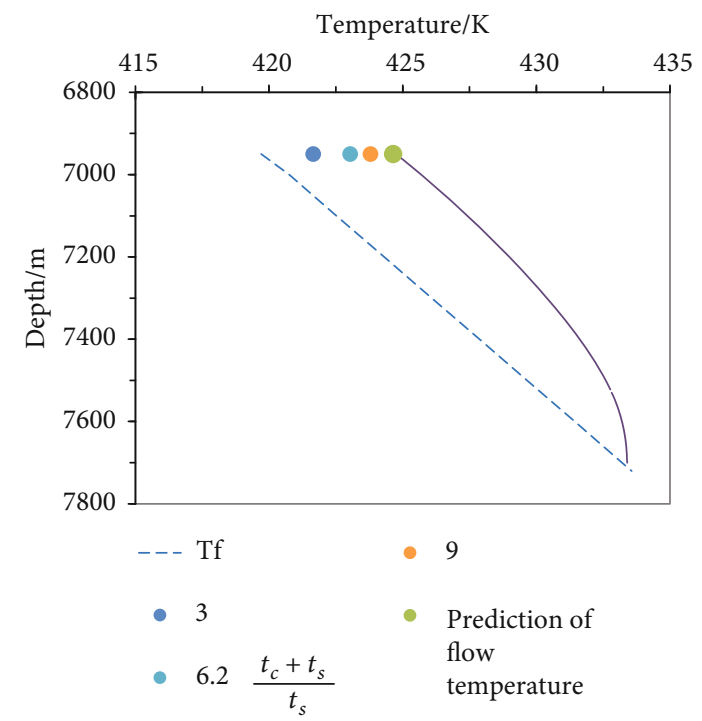

FIGURE 12: Temperature log and prediction temperature of well D.

\section{A Case}

In addition, using the abovementioned numerical simulation process, a method for predicting the flow temperature was successfully obtained using the temperature logs during the shut-in periods, and the equation for the reservoir depths using the differences between the bottom-hole static and flow temperatures. In practical application, the method proposed in this study can be divided into three steps: (1) data collection is performed; (2) flow temperature is calculated by the HM method; (3) the longitudinal length from the oil source to the bottom of the well is calculated using Eq. (9). The temperature logs of well D in the study area were used to predict the depth of the reservoir, as shown in Figure 12. The temperature log was measured at different times during the shut-in period, after stabilized production had been maintained for a long period of time. The bottom-hole depth of well $\mathrm{D}$ was determined to be $6,950 \mathrm{~m}$, and a predicted flow temperature of $424.9 \mathrm{k}$ was obtained using the Horner method. Since the difference in the static flow temperature was $6 \mathrm{k}$, and $h$ was determined to be $800 \mathrm{~m}$ using Eq. (9), the depth of the reservoir was $7,750 \mathrm{~m}$. On that basis, the temperature distribution in the cave was successfully obtained by a numerical simulation process in this study.

Seismic analysis has achieved promising results in describing the profile of fault-karst traps, which describes the internal fracture-cavity structure [27]. However, it cannot determine the specific depth of the reservoir by means of seismic analysis. The reservoir prediction results in this paper are compared with the profile of fault-karst obtained from seismic data (Figure 13). The predicted depth of $7750 \mathrm{~m}$ is $800 \mathrm{~m}$ different from the completion depth of $6950 \mathrm{~m}$. There is a large karst cave connected with the well on the profile of the seismic fault-karst traps, and oiliness is found in the karst cave and its underlying zone. It can be inferred from the figure that the source of oil in the well is deep and located far away from the well.

\section{Conclusion}

In this study, through the numerical simulations of the oil production processes, it was found that the well hole temperature measurements were related to the shut-in times. It was observed that following the shut-in period, the fluid temperature in the wellbore rapidly decreased, and this process was related to the production time. It could be seen that the longer the production time was, the more complex the temperature recovery process would be. Moreover, there was an obvious partitioning phenomenon observed in the semilog plot. However, when the production process was stable, the wellbore temperature increased rapidly and soon reached a 


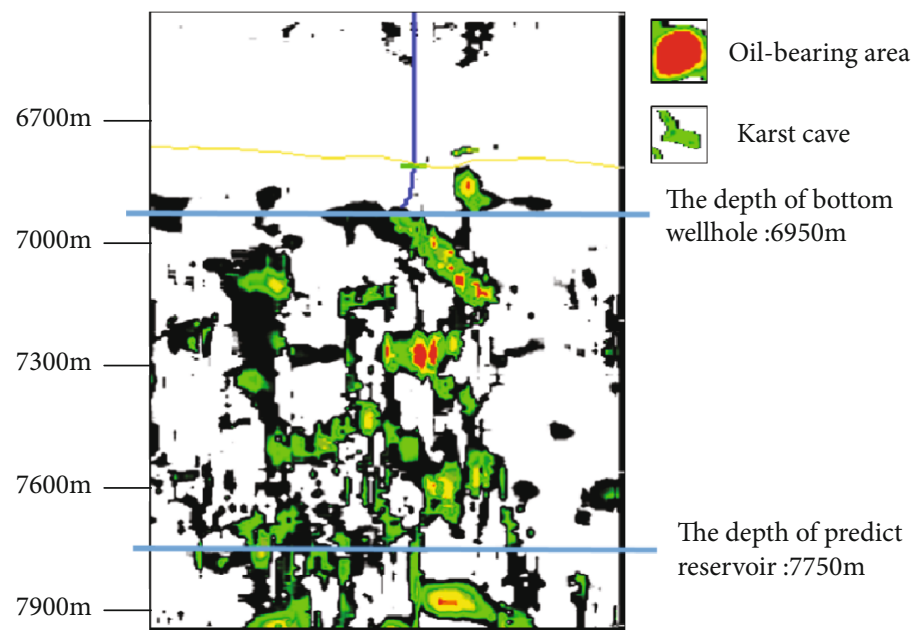

FIGURE 13: Reservoir prediction depth and seismic profile of fault-karst.

stability level. The temperature variations in the formations surrounding the wellbore were observed to be smaller than those in the wellbore, with the duration accompanying the entire production time.

In this research study, a well temperature recovery rule after shut-in was obtained via an HM. It was determined that during the development of karstic-fault reservoirs, the caves were the main flow channels. In addition, the changes in fluid temperatures were an important means by which to determine the reservoir depths. Therefore, in accordance with the differences in the bottom-hole static and flow temperature levels, the depths of reservoirs can be accurately predicted. The workflow of this study's proposed method was applied in a well in the Tahe Oilfield for verification purposes, with strong application results obtained.

\section{Data Availability}

The data used to support the findings of this study are available from the corresponding author upon request.

\section{Conflicts of Interest}

The authors declare that they have no conflicts of interest.

\section{Acknowledgments}

The project supported by National Natural Science Foundation of China (grant no. 2016ZX05053) and the Jilin province science and technology development plan outstanding young talent project (grant 20190103150JH).

\section{References}

[1] X. Shan, F. Tian, F. Cheng, C. Yang, and W. Xin, "Spectral Decomposition and a Waveform Cluster to Characterize Strongly Heterogeneous Paleokarst Reservoirs in the Tarim Basin, China," Water, vol. 11, no. 2, p. 256, 2019.

[2] F. Tian, X. Lu, S. Zheng et al., "Structure and filling characteristics of paleokarst reservoirs in the Northern Tarim basin, revealed by outcrop, core and borehole images," Open Geosciences, vol. 9, no. 1, pp. 266-280, 2017.

[3] Y. Liu, J. Hou, Y. Li, Y. Dong, X. Ma, and X. Wang, "Characterization of architectural elements of ordovician fracturedcavernous carbonate reservoirs, Tahe Oilfield, China," Journal of the Geological Society of India, vol. 91, no. 3, pp. 315-322, 2018.

[4] P. Yue, Z. Xie, H. Liu, X. Chen, and Z. Guo, "Application of water injection curves for the dynamic analysis of fracturedvuggy carbonate reservoirs," Journal of Petroleum Science and Engineering, vol. 169, pp. 220-229, 2018.

[5] Y. Li, J. G. Hou, and Y. G. Li, "Features and classified hierarchical modeling of carbonate fracture-cavity reservoirs," Petroleum Exploration and Development, vol. 43, no. 4, pp. 655-662, 2016.

[6] Y. Li and Z. H. Fan, "Developmental pattern and distribution rule of the fracture-cavity system of Ordovician carbonate reservoirs in the Tahe oilfield," Acta Petrolei Sinica, vol. 32, pp. 101-106, 2011.

[7] X. Lu, Y. Wang, F. Tian et al., "New insights into the carbonate karstic fault system and reservoir formation in the Southern Tahe area of the Tarim Basin," Marine and Petroleum Geology, vol. 86, pp. 587-605, 2017.

[8] Y. Li, D. G. Wang, Z. L. Liu, and X. P. Ma, "Development Strategy Optimization of Gas Injection Huff and Puff for FracturedCaved Carbonate Reservoirs," in SPE Kingdom of Saudi Arabia Annual Technical Symposium and Exhibition, Society of Petroleum Engineers, 2016.

[9] A. Lavrov, Lost Circulation: Mechanisms and Solutions, Gulf Professional Publishing, 2016.

[10] B. Pan, D. Li, G. Chen, Q. Wang, L. Ma, and S. Liu, "Numerical simulation of wellbore and formation temperature fields in carbonate formations during drilling and shut-in in the presence of lost circulation," Petroleum Science, vol. 11, no. 2, pp. 293-299, 2014.

[11] M. P. Anderson, "Heat as a ground water tracer," Ground Water, vol. 43, no. 6, pp. 951-968, 2005.

[12] M. O. Saar, "Review: geothermal heat as a tracer of large-scale groundwater flow and as a means to determine permeability field," Hydrogéologie, vol. 19, pp. 31-52, 2011.

[13] M. Klepikova, B. Brixel, and M. Jalali, "Transient hydraulic tomography approach to characterize main flowpaths and 
their connectivity in fractured media," Advances in Water Resources, vol. 136, p. 103500, 2020.

[14] M. V. Klepikova, T. Le Borgne, O. Bour, K. Gallagher, R. Hochreutener, and N. Lavenant, "Passive temperature tomography experiments to characterize transmissivity and connectivity of preferential flow paths in fractured media," Journal of Hydrology, vol. 512, pp. 549-562, 2014.

[15] G. Meyzonnat, F. Barbecot, J. A. Corcho-Alvarado et al., "High-Resolution Wellbore Temperature Logging Combined with a Borehole-Scale Heat Budget: Conceptual and Analytical Approaches to Characterize Hydraulically Active Fractures and Groundwater Origin," Geofluids, vol. 2018, Article ID 9461214, 19 pages, 2018.

[16] V. F. Bense, T. Read, O. Bour et al., "Distributed temperature sensing as a down-hole tool in hydrogeology," Water Resources Research, vol. 52, no. 12, pp. 9259-9273, 2016.

[17] M. Yang, Y. Meng, G. Li et al., "Estimation of Wellbore and Formation Temperatures during the Drilling Process under Lost Circulation Conditions," Mathematical Problems in Engineering, vol. 2013, Article ID 579091, 11 pages, 2013.

[18] J. A. Wong-Loya, E. Santoyo, and A. Andaverde, “A 3-D wellbore simulator (WELLTHER-SIM) to determine the thermal diffusivity of rock-formations," Computers \& Geosciences, vol. 103, no. 3, pp. 204-214, 2017.

[19] F. Ahammad, S. Mahmud, and S. Z. Islam, "Computational fluid dynamics study of yield power law drilling fluid flow through smooth-walled fractures," Journal of Petroleum Exploration and Production Technology, vol. 9, no. 4, pp. 2717-2727, 2019.

[20] I. M. Kutasov and L. V. Eppelbaumb, "Utilization of the Horner plot for determining the temperature of frozen formations - A novel approach," Geothermics, vol. 71, pp. 259-263, 2018.

[21] H. Tang, B. Xu, A. R. Hasan, Z. Sun, and J. Killough, "Modeling wellbore heat exchangers: fully numerical to fully analytical solutions," Renewable Energy, vol. 133, pp. 1124-1135, 2019.

[22] A. Q. Al Saedi, R. E. Flori, and C. S. Kabir, "Estimating the initial-formation temperature and flowing-temperature gradient with transient-temperature analysis: applications in gas reservoirs," Journal of Natural Gas Science and Engineering, vol. 66, pp. 126-137, 2019.

[23] E. Burlutskiy and C. K. Turangan, "A computational fluid dynamics study on oil-in-water dispersion in vertical pipe flows," chemical engineering research and design, vol. 93, no. 3, pp. 48-54, 2015.

[24] K. Pijush, I. M. Cohen, and D. R. Dowling, Fluid Mechanics Book, Academic Press, 6th edition, 2016.

[25] X. Li and J. He, "Research and Application of Radial Borehole Fracturing Based on Numerical Simulation. Geofluids," vol. 2019, Article ID 2167094, 16 pages, 2019.

[26] L. V. Eppelbaum and M. Kutasov, "Determination of formation temperatures from temperature logs in deep boreholes: comparison of three methods," Journal Of Geophysics And Engineering, vol. 3, no. 4, pp. 348-355, 2006.

[27] Z. Wang, H. Wen, G. X. Deng, W. Ding, and X. Wang, "Faultkarst characterization technology in the Tahe Oilfield,China," Geophysical Prospecting for Petroleum, vol. 58, pp. 149-154, 2019. 